\title{
DOE/ID/13988
}

Enhanced Geothermal Systems Project Development Solicitation

Final Report - 09/30/2000 - 02/01/2001

D. L. Nielson

May 2001

Work Performed Under Contract No. DE-FG07-00ID13988

For

U.S. Department of Energy

Assistant Secretary for

Energy Efficiency and Renewable Energy

Washington, DC

By

Drilling, Observation and Sampling of the Earth's Continental Crust, Inc. (DOSECC)

Salt Lake City, UT 
DOE/ID/13988

\section{ENHANCED GEOTHERMAL SYSTEMS PROJECT DEVELOPMENT SOLICITATION \\ FINAL REPORT \\ 09/30/2000 - 02/01/2001}

D. L. Nielson

May 2001

Work Performed Under Contract No. DE-FG07-00ID13988

Prepared for the

U.S. Department of Energy

Assistant Secretary for

Energy Efficiency and Renewable Energy

Washington, DC

Prepared by

Drilling, Observation and Sampling of the Earth's Continental Crust, Inc.

Salt Lake City, UT 


\title{
FINAL REPORT \\ SUBMISSION
}

\author{
FOR
}

ENHANCED GEOTHERMAL SYSTEMS PROJECT DEVELOPMENT SOLICITATION

DE-FG07-00ID13988

SUBMITTED

May 7, 2001

BY
DRILLING, OBSERVATION AND SAMPLING OF THE EARTH'S CONTINENTAL CRUST, INC.
(DOSECC)




\section{PROPOSAL SUMMARY}

All high-temperature geothermal systems distribute heat from zones of hot rock, normally high- level igneous intrusions and/or their crystalline products. However, geothermal fluids rarely come into contact with these igneous heat sources. Instead, there are zones of conductive heat transfer between the igneous heat sources and active hydrothermal circulation systems. These zones of heat conduction can be characterized as having fractures that are present, but not interconnected, resulting in a rock of low permeability. Current geothermal industry practice extracts energy from the actively convecting parts of geothermal systems. However, beneath these zones of active convection, in rocks that have high temperature but reduced permeability and fluid content, there is a tremendous amount of energy that is inaccessible using present technology.

The Enhanced Geothermal System concept is to develop the technology required to extract energy from the reduced permeability zones that underlie all high-temperature geothermal systems. We propose to develop this technology at The Geysers geothermal system in California. This is an ideal site for a number of reasons.

- The location and character of the zone of reduced permeability (here termed the High Temperature Zone or HTZ) is reasonably well understood.

- There are wells of opportunity that can be converted to deep injection status.

- There are wells for the production of steam and the monitoring of the success of this EGS project.

- There is an ample supply of injection water that will be provided by the Santa Rosa Geysers Recharge Pipeline.

- There is unused capacity at The Geysers power plants. An EGS project could result in production of additional electrical power in the near term.

Our concept is that injection wells will be drilled into the High Temperature Zone. The wells will identify fractures that are only poorly connected to the overlying reservoir. Water injected into these fractures will cause them to propagate through thermal contraction, increase in hydrostatic pressure and reduction of effective stress. The fractures will connect with the overlying Normal Temperature Reservoir (NTR), and steam will be produced from existing production wells. The injection water will generate high thermal quality steam while mitigating problems relating to high gas and chloride.

The most immediate candidates for EGS development are geothermal systems that are currently producing electricity. However once our EGS concept has been demonstrated technically, and development costs have been determined, an expansion of geothermal energy production is possible in any areas of high heat content. The advantage for this approach is that the infrastructure has largely been capitalized. The subsequent investment required for EGS is drilling deep injection wells and supplying injection water. This approach makes EGS an economically viable approach for an industry that has struggled to be cost-competitive.

The validation plan for our EGS concept involves drilling and injection into three separate wells. We have reviewed potential project sites at The Geysers and have 
identified a project area at Ottoboni Ridge that provides an ideal location for testing and evaluating our concept. The following plan is proposed.

- Well Ottoboni Federal 87A-2, presently completed as a production well in the lower part of the NTR, will be cleaned out and deepened into the HTZ using conventional air rotary drilling techniques. The well will be converted to injection, and the results of this injection will be monitored. This well will provide a baseline for both drilling techniques and simultaneous injection of water into both the NTR and the HTZ.

- A new well, designated Ottoboni Federal 51B-11 will be drilled vertically to the bottom of the NTR. A blank liner will be set and the well will then be continuously cored into the HTZ. This well will be dedicated to this project, and will allow the project team to evaluate different techniques, including directional drilling, forked completions and water injection scenarios without interrupting the operating schedule of Calpine.

- Applying what we have learned from deep injection into wells OF 87A-2 and OF 51B-11, well OF 45A-12 will be deepened into the HTZ and converted to injection. We anticipate that this deepening will use slim-hole drilling techniques.

- All three deep injection experiments will be accompanied by an extensive reservoir characterization and monitoring program that will include core logging, orientation of fractures, geochemistry of fluids, tracer tests, and seismic monitoring.

- The project will be actively managed to optimize the extraction of heat from the reservoir.

- Project costs will be actively evaluated to establish a cost basis that can be transferred to other geothermal reservoirs. 